\title{
DESAIN DAN SIMULASI INTERIOR KABIN PENUMPANG PESAWAT BOEING 737-300
}

\author{
Dwi Nugraheny, Eko Poerwanto, Tink Tonk Wicaksono \\ Jurusan Teknik Informatika \\ Sekolah Tinggi Teknologi Adisutjipto Yogyakarta \\ informatika@stta.ac.id
}

\begin{abstract}
Not only an aircraft technology is growing, a visual display in the cabin of the aircraft was already developed according to the need. Currently aircraft interior design can change the perception of many people about it. The designers are increasingly creative in designing aircraft interiors amazing. Interior design visualization Boeing 737-300 passenger cabin aims to provide an overview better visualization and can facilitate to understanding of the scope of a space including economy-class passenger cabin Boeing 737-300 aircraft in the form of $3 D$ design and simulation.
\end{abstract}

\section{Key Word : Boeing 737-300, Aircraft cabin Interior, 3d design, Simulation 3d.}

\section{Pendahuluan}

Pada perkembangan teknologi saat ini kita dituntut untuk mampu menguasai teknologi. Penguasaan teknologi tidak akan berjalan baik tanpa diiringi ilmu pengetahuan yang tepat. Perkembangan teknologi telah berimbas pada segala bidang termasuk industry tak terkecuali industry penerbangan. Saat ini, tidak hanya teknologi pesawat terbang yang semakin berkembang, tampilan visual dalam kabin pesawatpun sudah banyak berkembang sesuai dengan kebutuhan. Input visual yang akan mempengaruhi pengalaman kenyamanan. Informasi visual memainkan peran utama. Ini adalah kesan pertama kenyamanan.

\section{Tinjauan Pustaka}

Ruang kabin atau hanya disebut dengan kabin pada pesawat terbang merupakan salah satu bagian dari pesawat terbang yang berupa ruangan diperuntukan bagi para penumpang selama penerbangan. Dalam kabin pesawat komersil terdapat deretan tempat duduk di mana antar bagian umumnya dipisahkan oleh sebuah "gang" atau jalan bagi para penumpang untuk lewat dan para awak kabin yang biasanya membawa barang kebutuhan di atas pesawat.

\subsection{Desainer}

Desainer cenderung tampil sebagai seseorang yang terampil.Mereka mengambil dua ruang lingkup dalam dunia kerjanya, ruang lingkup secara visual dan secara konseptual. Mereka harus mampu meneliti garis, warna, volume, dan tekstur. Selain itu, harus mampu memerhatikan hubungan antara berbagai hal dan menemukan irama dalam repitisinya pada sesuatu yang mereka lihat.

\subsection{Simulasi}

Simulasi banyak digunakan untuk membantu meminimalkan resiko biaya hingga kesalahan fatal dalam dunia nyata, dimana teknologi simulasi terus ditingkatkan untuk berbagai penggunaan seperti latihan pilot pesawat terbang hingga ujicoba prototype produk baru. Salah satu dari penggunaan simulasi tersebut diantaranya adalah untuk memberikan sebuah gambaran dimana 
nanti dapat membantu persiapan-persiapan apa saja yang akan terjadi sehingga lebih menghemat biaya dan waktu, sampai nyawa manusia.

\subsection{Modelling 3D Pesawat Terbang}

Membuat model pada 3D serupa dengan memahat. Banyak teknik berbeda yang bisa digunakan untuk menciptakan objek dalam scene. Ada beberapa aspek yang harus dipertimbangkan bila membangun model objek dalam scene. Ada beberapa aspek yang harus dipertimbangkan bila membangun model obyek, semuanya member konstribusi pada kualitas hasil akhir. Hal-hal tersebut meliputi metode untuk mendapatkan atau membuat data yang mendiskripsikan obyek, tujuan. dari model, tingkat kerumitan, perhitungan biaya, kesesuaian dan kenyamanan, serta kemudahan manipulasi model.

Sebagian besar pesawat yang membawa kru, payload atau penumpang, barang dan banyak dari system itu dilakukan oleh banyak pesawat terbang yang beroperasi. Dalam sebuah penerbangan tentu seorang menginginkan kenyamanan selama penerbangan, ada banyak hal yang mempengaruhi tingkat kenyamanan kabin begitupun sebaliknya terdapat beberapa factor penyebab ketidaknyamanan kabin penumpang.

Model kenyamanan dapat membantu dalam menentukan di mana perhatian terbesar diperlukan. Hal ini tidak aneh, karena kita sudah melihat bahwa harapan dan pandangan pertama memainkan peran dalam pengalaman kenyamanan. Kursi penumpang seharusnya tidak hanya merasa nyaman dalam jangka panjang, tetapi juga terlihat nyaman. Bahkan, desain harus mendatangkan kenyamanan yang tinggi pada pandangan pertama.

\section{Desain Model Pesawat Terbang}

\subsection{Analisis Desain Kursi Penumpang Kelas Ekonomi Pesawat Boeing 737- 300}

Hampir semua maskapai di Indonesia menggunakan armada pesawat Boeing 737-300, pesawat boeing 737-300 memang dikenal sebagai pesawat terbaik pada kelas sejenisnya. Pada penulisan tugas akhir penulis mengambil design kabin pesawat dengan kelas ekonomi. Dan desain kabin pesawat boeing 737-300 telah memenuhi standar FAR.

\subsection{TaskAnalysis}

Task analysis adalah untuk menganalisa pekerjaan orang / pengguna yaitu tentang apa saja yang mereka / pengguna lakukan dan peralatan yang mereka gunakan. Serta apa saja yang pengguna harus ketahui.

\subsection{Workflow Pembuatan Aplikasi Simulasi}

Setelah memperoleh data masuk ke dalam tahap perancangan seperti blueprint dan tampilan graphic user interface. Pada tahap berikutnya yaitu modeling process di mana merupakan tahap pemodellan $3 \mathrm{~d}$ berdasarkan blueprint yang dibuat pada tahap perancangan sebelumnya.

\subsection{Perancangan Blueprint}

Teknik dalam perancangan blueprint disini menggunakan rulers yang disediakan oleh Adobe illustrator sehingga membuat penggambaran blueprint jadi lebih mudah dikarenakan setiap light segmen tool akan menempel pada setiap rule yang sudah disusun dalam kanvas kerja sehingga setiap garis / line akan menjadi tertata dan lebih rapi.

\subsection{Pemodellan 3D}

Hasil dari blueprintseat yang tadinya telah dibuat kemudian di kirim menuju aplikasi 3ds Max sebagai patokan dalam mendesain. Kemudian hasil blueprint pada viewport dengan cara pada menu viewport pilih viewport backround lalu pada background source klik folder dan pilih file blueprint. 


\subsection{Texturing}

Pada bagian model 3d highpoly disini merender hasilnya agar hasil nantinya akan di letakkan pada menu gallery aplikasi. Disini texture yang gunakan pada bagian highpoly berjumlah 6 yang sisipkan pada tiap model $3 \mathrm{~d}$.

\subsection{Export FBX}

Setelah selesai dengan tahap modelling dantexturing, modelling yang menggunakan konsep lowpoly akan langsung di import menjadi format fbx. Pengaturan untuk import fbx inipun terlebih dahulu dilakukan. Seperti pada pengaturan embedmedia sebelumnya harus di aktifkan terlebih dahulu agar texture yang telah di tanamkan pada model $3 \mathrm{~d}$ ikut terimport bersama model $3 \mathrm{~d}$.

\subsection{Unity}

Pada tahap unity ini sendiri mengkomposit setiap hasil asset-asset $2 \mathrm{~d}$ yang sebelumnya telah dibuat menggunakan adobe photoshop dan asset $3 \mathrm{~d}$ yang sebelumnya dibuat menggunakan $3 \mathrm{dsmax}$. Mem-build asset-asset tersebut hingga menjadi aplikasi simulasi yang berisikan image gambar dan simulasi interior kabin pesawat.

\section{Implementasi dan Pembahasan}

Tampilan ini merupakan tampilan awal pada aplikasi di mana pada tampilan ini aplikasi memberikan pilihan kepada user seperti simulation, gallery, theory, help dan exit kepada user dan user dapat memilih setiap option tersebut.

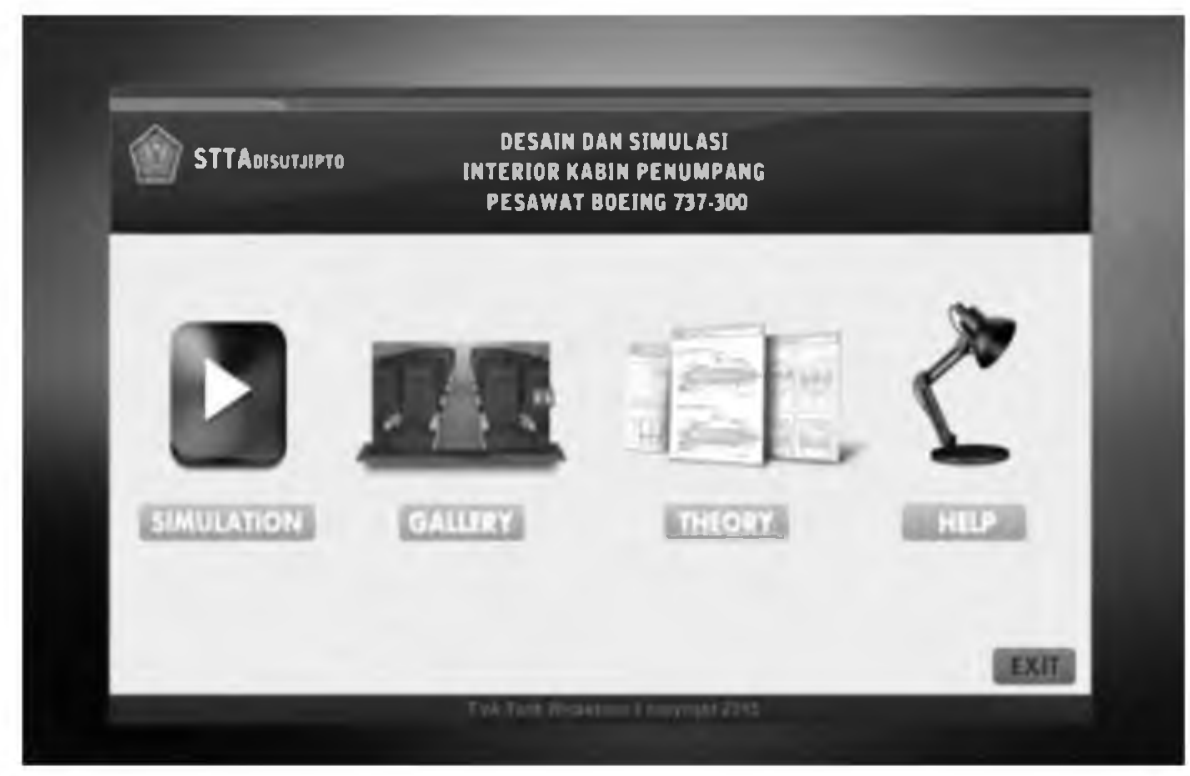

Gambar1.Tampilan Awal Aplikasi 


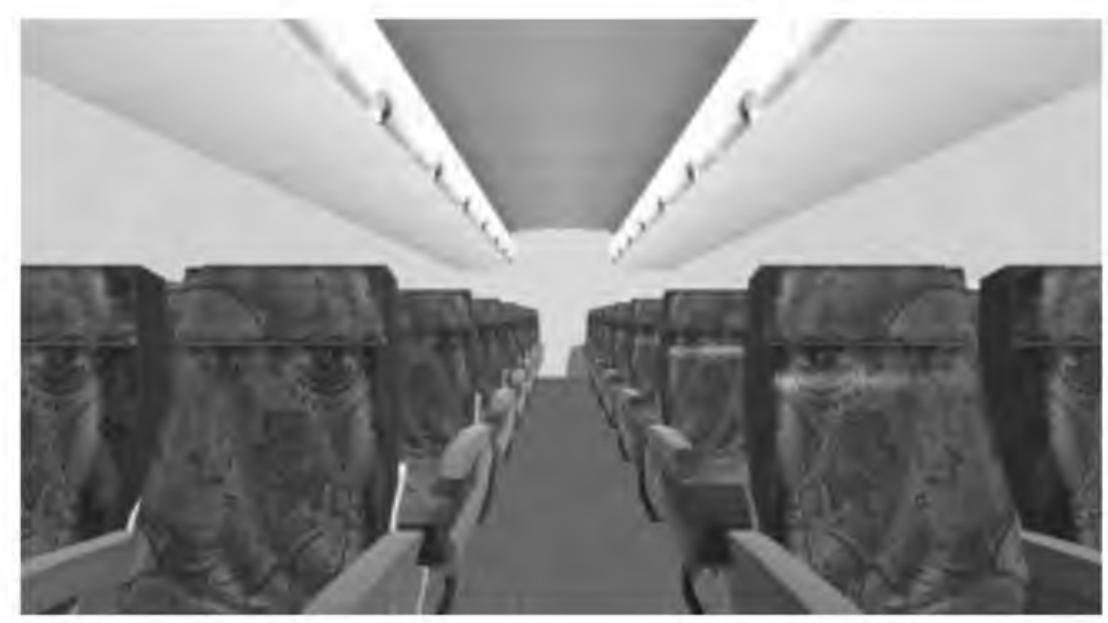

Gambar 2. Tampilan Simulasi Dari Sisi Depan

Pada saat user memilih icon simulation maka user akan langsung masuk dalam simulasi interior kabin pesawat boeing 737-300. User dapat menjelajahi kabin pesawat tersebut dan memantau setiap sudut kabin interior pesawat boeing 737-300, Seperti tampilan pada gambar 2, Gambar 3 dan Gambar 4.

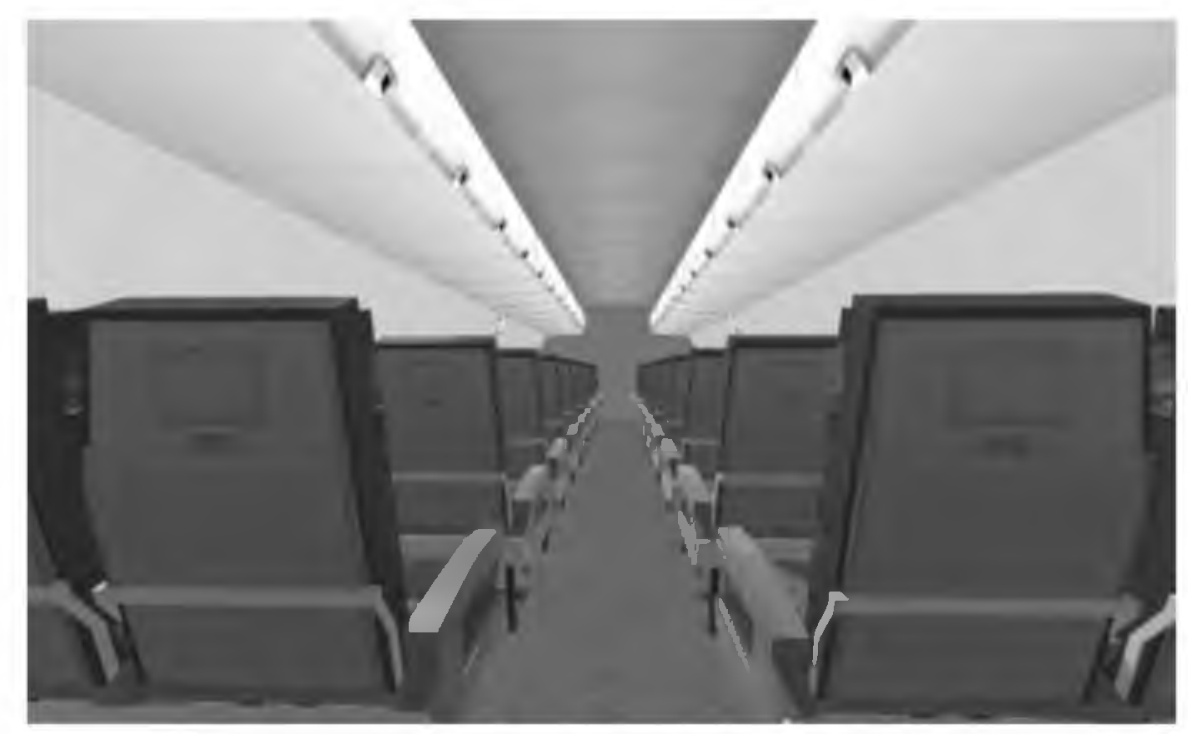

Gambar 3.Tampilan Simulasi Dari Sisi Belakang

Pada tampilan icon gallery user dapat melihat hasil gambar dalam bentuk realistic dalam berbagai tekstur yang berbeda yaitu diantaranya tekstur batik, vector dan lain-lain. Untuk dapat melihat hasil gambar user dapat menekan arah kanan ( ) pada keyboard untuk fordward dan menekan arah kiri ( 4 ) pada keyboard untuk backward. 


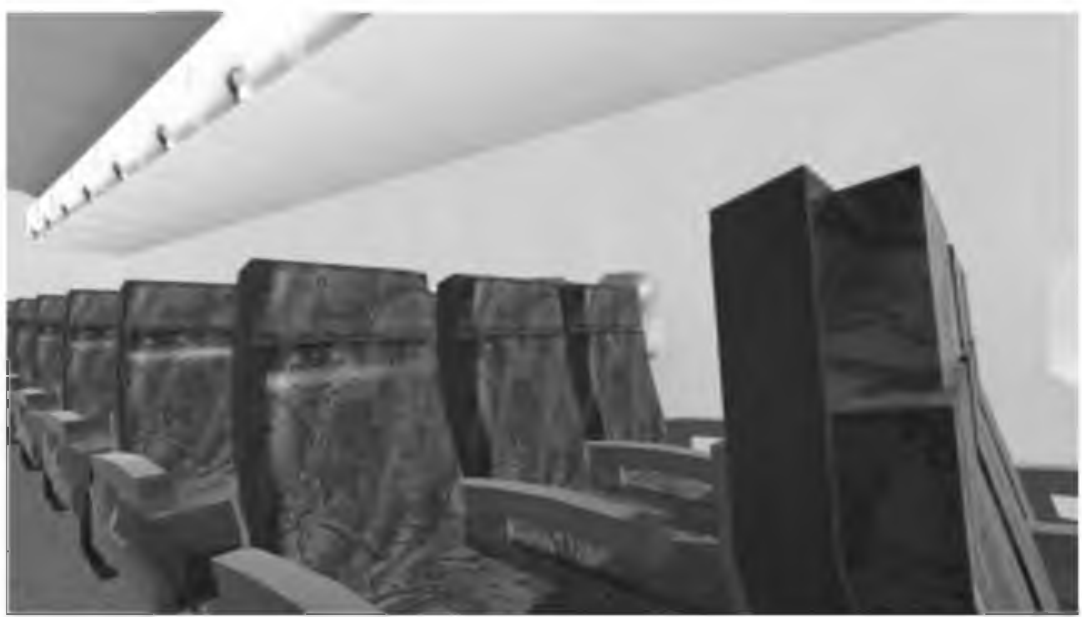

Gambar 4.Tampilan Dari Sisi Samping

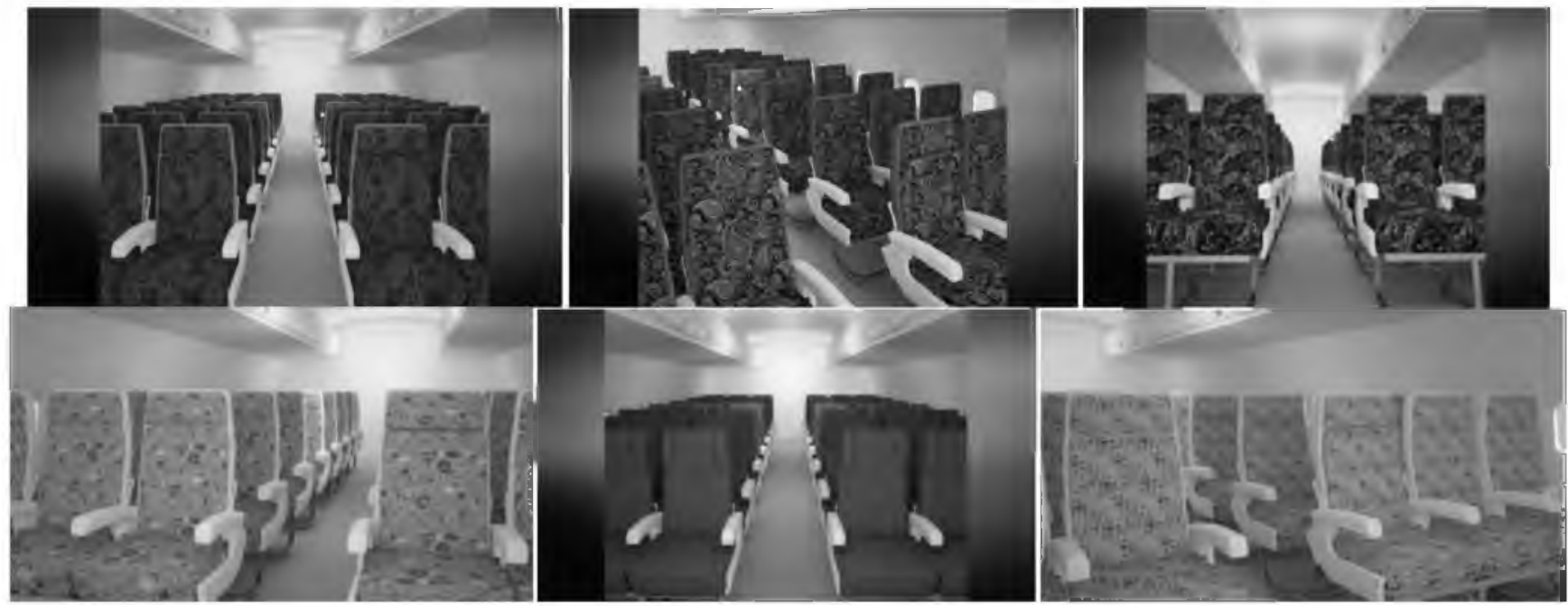

Gambar 5. Tampilan Yang Tersedia

Pada tampilan icon theory ini user dapat melihat atau membaca hal-hal yang berkaitan dengan konsep desain interior kabin pesawat boeing 737-300 secara teoritis termasuk aturan ukuran kursi pada kabin pesawat boeing 737-300.
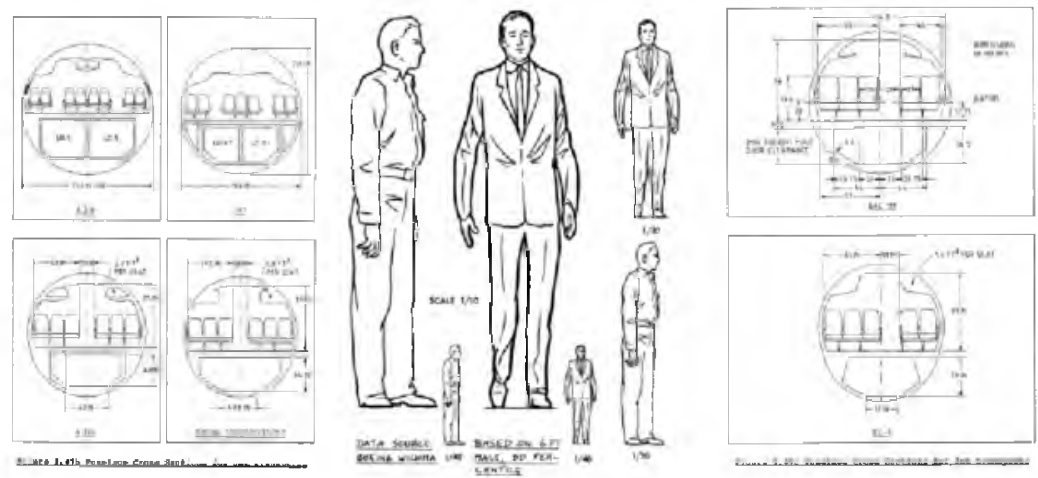

Gambar 6. Tampilan Yang Tersedia Pada Isi Icon Theory 
Pada tampilan icon help ini user akan dipandu untuk bagaimana cara menjalankan simulasi pada aplikasi ini, Seperti menekan Button "W" untuk gerakan maju, button "A" gerakan ke kiri, button "S" untuk gerakan ke kanan, untuk mundur dan button "D" untuk gerakan kanan. User juga dapat mengganti model bangku pesawat dengan menekan button 1 pada keyboard dan menekan tombol 2 pada keyboard untuk mengganti tekstur.

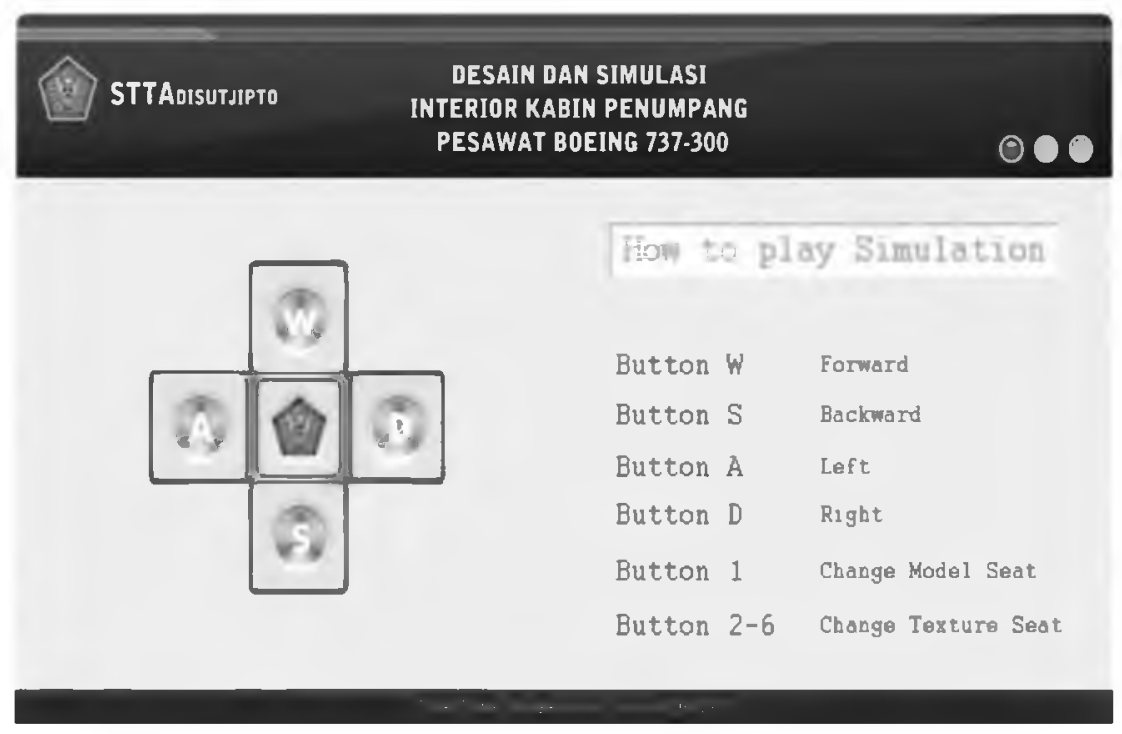

Gambar 7.Tampilan Help Pada Aplikasi

\section{Penutup}

\subsection{Kesimpulan}

Berdasarkan hasil analisa dari Aplikasi Desain dan Simulasi Interior kabin penumpang pesawat boeing 737-300 maka dapat disimpulkan:

1. Visualisasi design interior kabin penumpang pesawat boeing 737-300 dimulai dengan merancang blueprint menggunakan software adobe dalam bentuk gambar $2 \mathrm{~d}$, yang selanjutnya blueprint tersebut diubah menjadi model design $3 \mathrm{~d}$ menggunakan $3 \mathrm{ds}$ max.

2. Hasil desain $3 \mathrm{~d}$ kabin penumpang yang telah di buat dengan 3 dsmax sebelumnya kemudian di import ke dalama plikasi Unity di mana aplikasi memainkan perannya sebagai software yang mampu membuat simulasi yang dapat memonitoring kabin penumpang pesawat boeing 737300.

Simulasi kabin pada pesawat 737-300 ini diharap dapat memberi gambaran suasana pada kabin pesawat dalam bentuk simulasi berbasis $3 \mathrm{~d}$.

\subsection{Saran}

Dalam pelaksanaan tugas akhir ini, adapun beberapa saran yang dicantumkan adalah sebagai berikut:

1. Pada desain dan simulasi pesawat boeing 737-300 ini hanya mencakup pada kabin penumpang. Ke depannya simulasi juga akan mencakup kokpit pesawat

2. Desain untuk bangku pesawat penumpang hanya mencakup pada desain kelas ekonomi, Untuk ke depannya akan mendesain bangku pesawat penumpang untuk kelas bisnis dan vip.

3. Pada tekstur bangku pesawat hanya menggunakan tekstur bitmap, untuk ke depannya ditambahkan tekstur normal map agar hasil lebih detail.

4. Aplikasi hanya berjalan pada PC (Personal Computer) Untuk ke depannya akan berjalan pada mobile. 


\section{DaftarPustaka}

Alan Dix, 2004, Human Computer Interaction Third Edition, Pearson Prentice Hall.

Fendi, 2012, Adobe Illustrator Cs5 Untuk Orang Awam, Jakarta :Maxikom

Hendratman, Hendi, 2012, Tips n Trix Computer Graphics Design. Bandung :Informatika.

Hendratman, Hendi, 2012, The Magic of 3D Studio Max. Bandung : Informatika

Roedavan, Rickman, 2012, Unity Tutorial Game Engine. Bandung : Informatika.

TeguhWibowo, Ibnu, 2013, Belajar Design Grafis. Yogyakarta : BukuPintar.

Roskam, j., 1986, Part III: Layout Design of Cockpit, Fuselage, Wing an Empannage, Kansas.

Vink, Peter\&Brauer Klaus, 2001, Aircraft Interior Comfort and Design, Taylor and Francis Group, U.S.

https://alvinburhani.wordpress.com/2012/05/28/pengenalan-simulasi-2-2

diakseshariJumat, tanggal 29 Mei 2015 jam 23.17 WIB

http://nezlounya.blogspot.com/2009/12/modelling-character-3d.html

diakseshariJumat, tanggal 29 Mei 2015 jam 20.17 WIB 
Dwi Nugraheny, Eko Poerwant, Tink Tonk Wicaksono 